\title{
El mobbing académico, fenómeno ignorado y de responsabilidad conjunta: estudio de caso en una universidad estatal en Costa Rica
}

\author{
Academic mobbing, an ignored \\ phenomenom and a shored responsibility: A \\ case study at a state university in Costa Rica
}

\section{Resumen}

El mobbing es una práctica negativa que puede presentarse de diferentes maneras en las organizaciones. Este fenómeno consiste en el sometimiento de una persona a un ataque sutil y sistemático, directo o indirecto, durante al menos seis meses, con el objetivo último de que la víctima abandone su trabajo o se "vuelva invisible" en la institución. Esta investigación presenta un esfuerzo exploratorio y descriptivo sobre la conceptualización del mobbing, sus causas y posibles consecuencias para la víctima y la organización, en este caso, la academia; así también, se reflexiona sobre los resultados que el acoso laboral puede ejercer sobre la cultura organizacional. Además, el estudio recabó datos de dos docentes universitarios que afirman haber sufrido mobbing, uno con plaza laboral a tiempo indefinido y otro a tiempo definido, lo que permitió apreciar que las consecuencias del acoso representan situaciones muy complejas que se mantienen a lo largo de los años.

Palabras claves: mobbing, organización, cultura organizacional, academia, acoso 


\begin{abstract}
Mobbing is a negative practice in organizations. This phenomenon consists in having a person subtly and systematically attacked, directly or indirectly, at least for six months, aspiring to make the victim quit his/her job or force him/her into "organizational invisibility." This research presents an exploratory and descriptive work on mobbing, its causes and possible consequences for the victim and the institution for which s/he works, in this case, the academia; moreover, it is concerned with the effects it may have on organizational culture. Besides, this study collected information of two faculty members who claim to have suffered from mobbing, one of them holding a tenure position while the other does not. This case study allowed the research to understand that the consequences of mobbing are very complex and they remain with the subjects for many years.
\end{abstract}

Keywords: mobbing, organization, organizational culture, academia, harrasement

\section{Introducción}

$\mathbf{E}$ 1 ingreso a la academia (universidad) a impartir lecciones es para muchos docentes un sueño hecho realidad. Poder crecer académicamente, ser parte de un entorno libre de todo tipo de discriminación, así como pensar que en la universidad los docentes son parte de un networking de apoyo, podrían ser apreciaciones no tan certeras de alguien externo a estas instituciones. Hay momentos en que se cuestiona y critica negativamente a académicos con exitosa trayectoria en todos los ámbitos universitarios por limitarse a impartir lecciones y participar solamente en reuniones de tipo obligatorio; sin embargo, casi nunca se consideran las razones que les llevaron a la toma de tales decisiones. Algunos podrían afirmar que el/la docente se convierte en un profesional "fantasma," todos saben que llega a impartir lecciones pero está ausente (aunque presente) del resto del quehacer universitario. Este escenario puede ser considerado como el efecto que el denominado mobbing académico ejerce sobre miembros de este tipo de organización.

Seguin (2016) afirma que "Successful mobbing leads to any of a number of outcomes: the targets commit suicide, are dismissed (or often at universities, being denied tenure), resign, retire early, take permanent or recurring sick leave (the last three being the most common cases for university professors), or have all their responsibilities withdrawn (as in the case of sidelined senior public servants)"'.

1 Cuando el mobbing es exitoso, este deriva en cualquiera de los siguientes resultados: la persona considerada el blanco del ataque se suicida, se da por finalizado el contrato laboral (o a menudo en la Universidad se les niega una plaza en propiedad), renuncian, se acogen a su pensión tempranamente, se incapacitan permanentemente o cada cierto tiempo (siendo estas últimas tres razones los casos más comunes en docentes universitarios), o solicitan no tener que asumir ningún tipo de responsabilidad (como en el caso de empleados públicos marginados con antigüedad). (Mi traducción) 
Consecuentemente, se puede asegurar que este fenómeno causa efectos graves, para algunos gravísimos, en sus vidas, tanto personales como profesionales. Por lo tanto, y debido a la poca discusión de este tema, ya sea porque las personas tienen temor a represalias o porque aún están en un periodo de recuperación, este artículo busca discutir las características fundamentales del fenómeno del mobbing en un escenario académico universitario, invisibilizado en la mayoría de los casos, así como también reflexionar sobre por qué este es habitual y practicado por miembros de la comunidad académica. Igualmente, se considerarán las posibles consecuencias para la persona que sufre de mobbing, en particular, y para la organización, en general.

\section{¿Cuándo inicia el estudio del mobbing’}

El estudio sistemático de este fenómeno se originó en la primera parte de los años ochenta. Fondevila (2008) comenta que "Es probable que haya sido abordado por primera vez por C.M. Brodsky (1976) pero no fue tratado como objeto científico hasta 1984, cuando se publicó el informe del National Board of Occupational Safety and Health de Estocolmo" (p. 306) por Leymann y Gustafsson. En 1976, Brodsky hace referencia al hostigamiento que los trabajadores sufrían en Suecia, tales como extensas horas de trabajo, agotamiento físico y posibles accidentes laborales entre otros. Por su parte, Lorenz, en 1963, utilizó el término mobbing para aludir a un fenómeno de la vida animal en el que a un grupo de animales se les integra un nuevo miembro a quien atacan hasta causar que este huya.
Leymann, quien se considera el padre de esta materia, decidió utilizar el mismo término, mobbing, para señalar un tipo de comportamiento similar por parte de las personas en el mundo laboral. En 1998, Hirigoyen, en Francia, utiliza el término acoso moral para referirse a agresiones que pueden presentarse en cualquier escenario de la vida del ser humano y que son difíciles de percibir. En España, Piñuel y Zavala estudian los orígenes de este fenómeno y así también reflexionan sobre los efectos que este tiene en las relaciones laborales de los individuos. Barón Duque, otro investigador español, relaciona el mobbing con el concepto de poder y cómo adquirirlo, por lo que para él, el enfoque se inclina hacia los valores morales de las personas.

Si bien los problemas de violencia y poder han sido parte de las relaciones entre individuos en diferentes escenarios de la vida, el estudio del mobbing como sinónimo de acoso psicológico en el trabajo adquiere cada día mayor notabilidad por los efectos que puede tener en la víctima, las organizaciones y la sociedad. Sin embargo, a pesar de que existe un gran interés en solucionar este fenómeno en el ámbito privado, ¿por qué no se estudia a profundidad la relación causaefecto de este en la academia y otras instituciones públicas? De acuerdo con Seguin (2016), "In truth, universities are breeding grounds for $m o b$ bing (...) In many faculties, mobbing has gained popularity as a work method"'; así tambien, Marente y Guillén (2008) mencionan que "En estudios llevados a cabo

2 En realidad, las universidades son campos de reproducción de mobbing (...) En muchas facultades, el mobbing ha ganado popularidad como método de trabajo. (Mi traducción) 
por los profesores Leyman (1996) y Piñuel y Zabala (2001) se señala al profesorado como los trabajadores con mayor incidencia de mobbing" (p. 169). En caso de que esta sea una realidad que también viven docentes en instituciones estatales de educación superior en Costa Rica, pero de la que nadie habla, se podría afirmar que se vive en un espejismo y que la supuesta grandeza moral de estas organizaciones y su retribución social no lo son tanto.

\section{Metodología y sujetos de investigación}

Este trabajo de investigación se enfocó en un estudio de caso cualitativo, exploratorio y descriptivo, al sostenerse entrevistas en profundidad y análisis documental a dos individuos que sufrieron de mobbing en una única institución de educación superior estatal, y en describir el fenómeno. De acuerdo con López, Vásquez y Montes (2010):

Los estudios de caso pueden ser utilizados para proponer una teoría o generar contenidos teóricos que expliquen las lagunas en la investigación científica sobre el mobbing, permitiendo encapsular situaciones de la vida real y contrastar hipótesis en relación directa con los fenómenos estudiados a medida que estos se desarrollan en la práctica real (p. 217).

Así también, la escogencia de ambos individuos se basa en su pertinencia teórica y su posibilidad de acceso a la información. Razonando el primer criterio, se consideran casos probables que pueden ser o han sido ya replicados en la organización; con respecto al segundo criterio, se estima que contar con personas anuentes a conversar sobre este tema es un logro debido al temor que pudiera existir entre colaboradores de la institución.

\section{¿Qué es el mobbing? ¿Cuál es su relación con la academia?}

El mobbing es aquel intento sistemático y repetido que busca el daño de un individuo o grupo de individuos, quienes tienen dificultad para defenderse y tiende a existir un desequilibrio de poder entre el acosador y las víctimas. Barón, Munduate y Blanco (2003) manifiestan que "Dicha conducta es reiterativa y persistente en el tiempo, llegando a adoptar métodos de influencia muy diversos, que van desde la infravaloración de las capacidades del trabajador, hasta su desbordamiento por la asignación de tareas irrealizables, pasando por agresiones como la ocultación de información, la difamación o el trato vejatorio" (p. 72). Como puede notarse, las acciones que el agresor inflige a la víctima son de varios tipos y se ubican en un continuum que se presenta desde la solicitud de realizar lo imposible hasta la inactividad total. Según Peralta (2004), para que una práctica sea considerada como mobbing, debe de presentar las siguientes particularidades: "(1) repetitiva; (2) basada en un desequilibrio de poder; (3) una intención de causar miedo o hacer daño; (4) involucrar abuso físico, psicológico o verbal; y (5) no ser provocada por la víctima" (p. 114). Esta última característica mencionada por Peralta es de vital interés ya que por lo general "en la mayoría de los casos el mobbing afecta a trabajadores brillantes, bien valorados, cumplidos y participativos, personas activas y con gran carisma a las que intenta presentar como poco inteligentes, 
holgazanas y conflictivas (Flores, Valderrabano y Hernández, 2007, p. 76).

\author{
Para Olmedo y González (2006), es funda- \\ mental destacar que:
}

Quizá lo más relevante del concepto es que dicho acoso moral es una violencia en pequeñas dosis, que no se advierte y que, sin embargo, es muy destructiva. Es decir, si tomamos por separado cada acción de ataque, no resulta realmente grave; es el efecto acumulativo de micro traumatismos frecuentes y repetidos lo que constituye la agresión. En este sentido conviene tener en cuenta que no sólo hacen daño insultos directos, que son agresiones demasiado obvias, sino también las insinuaciones y comentarios mal intencionados así como los actos de no-comunicación (ignorar un saludo, no responder una pregunta, actuar como si determinada persona no estuviera presente, etc.). Estos pequeños actos agresivos que suelen comenzar con una sencilla falta de respeto se transforman progresivamente en verdaderas conductas perversas que tienen graves consecuencias para la salud psicológica de la víctima (p. 110).

Cada una de las pequeñas acciones que el agresor provoca a la víctima, con el paso del tiempo, incrementan su impacto en el individuo hasta que la persona se ve afectada de manera irreparable. Más aun, una característica esencial que se puede destacan es que el mobbing nunca va a ser manifiesto, todos esos "microtraumatismos frecuentes" son imperceptibles. El sujeto 2 de esta investigación nunca había escuchado el término mobbing hasta que en una cita médica, por problemas ocasionados por la situación que estaba viviendo, lo conoció. De acuerdo con esta persona:

Yo no sabía qué era lo que me pasaba, la doctora general que me había atendido anteriormente me dijo que sufría de burnout ${ }^{3}$ por lo que hice una cita con un doctor privado. Después de una conversación y revisión detallada el doctor me dijo: "Lo que le pasa a usted es que está sufriendo de mobbing, no de burnout como le diagnosticó la colega." Cuando mencionó esa palabra no entendí que era hasta que el doctor fue explicándome que era y como me afectaba. En ese instante entendí lo que hasta entonces no había entendido y me di cuenta de que no había solución. A partir de ese momento, esperaba cada día y cada semana algo, y ese algo era una llamada de atención, una carta muy sutil refiriéndose a cualquier tema o cosa de manera negativa, una convocatoria a reunión en la que no me dirigían la palabra o no me permitían participar. Llegó un momento en que algunas personas sentían temor

3 De acuerdo con Mantilla y Díaz (2012), el burnout es definido como un "síndrome por estrés interpersonal crónico en el ejercicio laboral. Al hablar de síndrome nos encontramos ante un cuadro sintomático y no ante una enfermedad definida. Dicho síndrome se caracteriza por sentimientos de fatiga, desánimo, baja moral, desilusión, despersonalización y autoeficacia reducida, vinculados a situaciones de demandas vividas como excesivas en el ámbito laboral. (...) el síndrome está configurado por tres dimensiones: Agotamiento, Despersonalización y Realización. (...) el Agotamiento se refiere a las sensaciones de sobreesfuerzo físico y cansancio emocional como consecuencia de las continuas interacciones que los trabajadores deben de mantener entre ellos, así como con los clientes. La Despersonalización supone el desarrollo de sentimientos, actitudes y respuestas negativas y distantes hacia otras personas (compañeros de trabajo, superiores, clientes, etc.). Por último, la baja Realización conlleva la pérdida de confianza en la realización personal y la presencia de un negativo autoconcepto como resultado de situaciones problemáticas en el ámbito laboral" (p. 260). 
de hablarme delante de mi superior y así me lo hicieron ver. Soporté la situación hasta que no pude más y renuncié a mis funciones.

Tal como este individuo comenta, estos "microtraumatismos" generaron una situación insoportable que lo obligaron a tomar decisiones que en otro momento no hubiera tomado. El conflicto entre las partes no tuvo solución y la persona que causaba las agresiones se enfocó en marginar a la víctima y generar redes de apoyo que fortalecieron su nociva acción.

La "no-comunicación" que Olmedo y González mencionan es uno de los hechos que puede llegar a tener mayor impacto sobre un académico que sufre de este tipo de hostigamiento porque el/ella no "comprende" el origen de la situación: ¿Por qué no me habla? ¿Por qué me ignora? Probablemente, el/la docente dentro de su cándido paradigma profesional considera las siguientes premisas como ciertas:

- La labor en una institución de educación superior pública está caracterizada por el respeto hacia los demás, el libre pensamiento y la apertura a la diversidad (en todos los campos) entre otras, lo que le permite procesos de comunicación directos y claros con los individuos que conforman la organización (o al menos la mayor parte de ellos).

- Los individuos que integran la comunidad docente son personas que se han formado académicamente y que de acuerdo con sus posibilidades e intereses profesionales poseen maestrías, doctorados y posdoctorados; conocimiento que les proveería con las herramientas necesarias para relacionarse adecuadamente con sus colegas y autoridades universitarias.

- Se valora la originalidad y se promueve la independencia para realizar proyectos académicos, actividades de alcance social, de investigación y de trabajo en el aula. Aun cuando se pueden generar situaciones de "celos profesionales", los educadores, al poseer grados académicos superiores, están capacitados para trabajar de manera adecuada de manera tal que ningún miembro de la organización se vea afectado por anteponer intereses personales a la generación de conocimiento.

- Se presume que en el ámbito de educación superior, y especialmente en la pública, no debería existir un fenómeno tan pernicioso como lo es el mobbing. En caso de que surgiera, la comunidad académica se negaría a participar de él y lo erradicaría.

Lastimosamente, estas premisas que tienden a asumirse como verdaderas no siempre lo son. Es así como para Ibarra, Escalante y Mendizabal (2015), "Si bien el acoso es una condición por la que puede transitar cualquier persona en sus relaciones de trabajo (...) los profesores universitarios son más propensos que otros profesionales a padecerlo." De la misma manera, Justicia et al. afirman que: "En el caso específico del sector educativo, los estudios lo señalan como uno de los más afectados" (p. 458). Para estos mismos autores:

Las formas más frecuentes de acoso laboral en la universidad son las siguientes: ocultar información $(55,3 \%)$, infravalorar el trabajo $(55,3 \%)$, no 
tener en cuenta la opinión de las personas $(53,7 \%)$, criticar sin fundamento $(46 \%)$, infravalorar el esfuerzo $(45,3 \%)$, exclusión social $(41,7 \%)$, limitar las tareas sin justificación (37\%), propagar rumores falsos $(34,7 \%)$, la sobrecarga de trabajo $(31,7 \%)$ (p. 460).

Este tipo de acciones pueden presentarse de tres maneras. La primera es la descendente, en donde el acosador tiene una posición jerárquica superior a quien se convierte en su víctima; la horizontal, en la que tanto el acosador como la víctima ocupan la misma posición jerárquica; y la ascendente, cuando la posición del acosador es inferior a la de la víctima. Tal como afirma Seguin (2016): "If you're a university professor, chances are fairly good that you have initiated or participated in mobbing. Why? First, because mobbers are not sadists or sociopaths, but ordinary people; second, because universities are a type of organization that encourages mobbing; and third, as a result, mobbing is endemic at universities ${ }^{4}$." Tal como ella manifiesta, probablemente se ha iniciado y/o participado de este fenómeno de manera consciente, en algunos casos, y en otros de manera inconsciente por medio de la complicidad en murmuraciones, burlas y rumores, entre otras acciones. Parecería que la apreciación de Seguin es excesiva al afirmar categóricamente que la universidad promueve este tipo de acoso; sin embargo, no lo es tanto, tema que será razonado en el apartado estrategias del mobbing.

4 "Si usted es un docente universitario, lo más probable es que haya iniciado o participado del mobbing. ¿Por qué? Primero, porque las acosadores no son ni sádicos ni sociópatas, sino gente promedio; Segundo, porque las universidades son el tipo de organización que promueve el mobbing; y tercero, porque el mobbing es endémico en las universidades." (Mi traducción)

\section{¿Cuál es el fin último del mobbing?}

Para Pinzón de Bojana y Atencio (2010), el fin último del mobbing es el "destruir las redes de comunicación de la víctima o víctimas, destruir su reputación, perturbar el ejercicio de sus labores y lograr que finalmente esa persona o personas acaben abandonando el lugar de trabajo" (p. 141). De la misma manera, Flores et al. (2007) afirman que además de buscar que la víctima renuncie a su trabajo, el acosador busca

(...) deteriorar el rendimiento y el desempeño del trabajador mediante trampas, desestabilizándolo psicológicamente, creando argumentos inexistentes anteriormente para utilizarlos en su contra. De esta manera se acusa al trabajador de bajo rendimiento, baja productividad, ausentismo o bien de comportamientos erráticos, todo ello como producto de la desestabilización a la que se le ha sometido. (...) Estas técnicas tienen en común que con ellas se intenta agobiar, calumniar y atacar el trabajo, las convicciones y la vida privada de la víctima, aislándola, estigmatizándola y amenazándola (p. 75).

Pareciera que el mobbing tiene como fin último que la víctima abandone su trabajo, o en el caso del docente universitario, renuncie a aquellas responsabilidades que no sean impartir lecciones. Sin embargo, debe de considerarse que para que un individuo llegue a tomar esta decisión, su autoestima profesional así como su reputación han sufrido lesiones. El sujeto 1 de esta investigación manifestó su deseo de abandonar su lugar de trabajo debido a que para esta persona la situación fue intolerable: 
Llegó un momento en que no sabía qué podía hacer. Busqué soluciones y traté de asumir de la mejor manera los trabajos/tareas asignadas pero nunca logré "hacer las cosas bien." Todo lo que hacía parecía estar mal hecho. Pensé muchas veces renunciar e irme pero no creí que fuera justo. Acudí a diferentes oficinas de la institución para buscar ayuda pero nunca la recibí. Al día de hoy, y después de muchos correos, aun no recibo respuesta sobre mi situación, de la oficina que debería de velar por mi bienestar, ya han pasado casi cuatro años. En otra oficina, un abogado (asesor legal) me recomendó mantener un perfil muy bajo para evitar mayores conflictos porque, yo, no mi superior, llevaba las de perder... al final, terminé medicado y con muchas afectaciones a mi salud como alergias, taquicardia, insomnio, migrañas y depresión, de esta última aún estoy tratando de salir.

Si una persona ha transitado por estas situaciones, cabría cuestionarse si el acosador está consciente de que el daño que inflige al trabajador va más allá de la labor y reputación profesional y que las consecuencias, en general, que esta situación acarrea a la víctima serán difíciles de solucionar para la mayoría, mientras que para algunos será irrealizable. Arciniega (2009) declara que:

Los hallazgos muestran que el acoso moral en el trabajo no es fácilmente visible en la organización, ni siquiera en los primeros niveles de cultura organizacional, y es que la dinámica del mobbing resulta a partir del juego de la comunicación que involucra el manejo y control de las emociones de los afectados (...) Cada actuación, acto de habla y texto escrito está inmerso en un entramado de intencionalidades que en el caso del acoso moral es siempre encuadrable en lo negativo hacia el individuo y su destrucción moral y hasta física (p. 121).

El desgaste no le permitirá a la persona acosada enfrentar la situación de manera apropiada, especialmente si el acoso es casi imperceptible para la mayoría de miembros de la organización, lo cual le resultará a la víctima más doloroso.

Para Martel y Mateo (2012) "resulta paradójico que las personas deban trabajar para ganarse el sustento y que, precisamente, esa lucha por la supervivencia pueda significar la causa de su hundimiento y ruina moral" (p. 169). Casi siempre, cuando una persona busca y encuentra un trabajo es debido a que necesita un salario para poder hacer frente a sus necesidades económicas, sociales y culturales, por lo que es incomprensible que se le destruya cuando trata de realizar su labor profesional. En el ámbito universitario se puede pensar que este tipo de acoso podría perseguir principalmente:

- Evitar que una persona adquiera una plaza de tiempo indefinido.

- Buscar la invisibilización de la víctima, retirándole todo tipo de responsabilidad que no sea impartir lecciones $\mathrm{y}$ evitando que se le asignen nuevos cursos (un congelamiento).

- Atribuir a la posible víctima características tales como problemática, difícil, vagabunda, contestataria, preguntona, egoísta y mentalmente desequilibrada, entre muchos otros adjetivos, para así evitar que la persona se distinga por su labor profesional. 
Las anteriores son algunas posibilidades, pudiendo haber de otro tipo. El periódico La Nación, en su sección "Foros" de fecha 17 de agosto de 2013, reflexiona sobre este tema, enfocándolo en la realidad costarricense, y afirma que "El acoso laboral en Costa Rica es una realidad. Las instituciones públicas están saturadas de acosadores y acosados. Las víctimas son trabajadores paralizados, sin producción, enfermos, que esperarán, incapacitados, hasta que llegue su jubilación." En caso de que esta declaración pudiera comprobarse, se podría entonces analizar, desde una perspectiva diferente a las usualmente utilizadas, la calidad de servicio que se recibe en algunas instituciones del sector público, y es cuando entonces se aclararían los nublados del día.

\section{Fases del mobbing}

Al igual que en otros fenómenos, este tipo de hostigamiento va modificándose a través del tiempo. No hay que olvidar que una de las características del mobbing es la repetición de microagresiones por periodos definidos de tiempo hasta que se alcance el objetivo último que es el abandono del trabajo, la invisibilización del trabajador o el acogerse a la pensión (entre los que más destacan). Existen diferentes modelos para explicar las fases que componen el mobbing. Las siguientes son 2 propuestas que buscan comprender este fenómeno en el tiempo:

\section{Cuadro 1. Fases del mobbing}

\begin{tabular}{|c|c|c|c|c|c|c|}
\hline & Fase 1 & Fase 2 & Fase 3 & Fase 4 & Fase 5 & Fase 6 \\
\hline $\begin{array}{l}\text { Leymann } \\
\text { (1996) }\end{array}$ & \begin{tabular}{|l|} 
Incidentes \\
críticos: \\
Se da una \\
situación de \\
conflicto que \\
no se resuelve \\
adecuada- \\
mente.
\end{tabular} & $\begin{array}{l}\text { La estigma- } \\
\text { tización y } \\
\text { persecución } \\
\text { sistemática: } \\
\text { Se busca } \\
\text { señalar a la } \\
\text { persona que } \\
\text { se considera } \\
\text { como una } \\
\text { amenaza o } \\
\text { molestia. }\end{array}$ & $\begin{array}{l}\text { Gestión o } \\
\text { Dirección del } \\
\text { personal: } \\
\text { Se percibe } \\
\text { la situación } \\
\text { como un } \\
\text { conflicto } \\
\text { personal y } \\
\text { por lo general } \\
\text { a la organi- } \\
\text { zación le es } \\
\text { más "fácil" } \\
\text { deshacerse } \\
\text { de la persona } \\
\text { problemática. }\end{array}$ & $\begin{array}{l}\text { Expulsión } \\
\text { de la vida } \\
\text { laboral: } \\
\text { A la víctima } \\
\text { se le separa } \\
\text { de su trabajo. }\end{array}$ & & \\
\hline
\end{tabular}




\begin{tabular}{|c|c|c|c|c|c|c|}
\hline & Fase 1 & Fase 2 & Fase 3 & Fase 4 & Fase 5 & Fase 6 \\
\hline $\begin{array}{l}\text { Martel } \\
\text { y Mateo } \\
(2012)\end{array}$ & $\begin{array}{l}\text { Seducción: } \\
\text { Se busca } \\
\text { conocer a la } \\
\text { víctima y sus } \\
\text { debilidades. }\end{array}$ & $\begin{array}{l}\text { Conflicto: } \\
\text { Se presenta } \\
\text { una mala } \\
\text { resolución de } \\
\text { un conflicto } \\
\text { que lleva al } \\
\text { mobbing. }\end{array}$ & $\begin{array}{l}\text { Acoso: } \\
\text { Se presentan } \\
\text { acciones su- } \\
\text { tiles, difíciles } \\
\text { de percibir } \\
\text { de manera } \\
\text { repetitiva e } \\
\text { intencional } \\
\text { que van } \\
\text { afectando a } \\
\text { la víctima. } \\
\text { Muchas veces } \\
\text { el acosador } \\
\text { busca y en- } \\
\text { cuentra apoyo } \\
\text { en otras } \\
\text { personas de } \\
\text { la organi- } \\
\text { zación para } \\
\text { desacreditar a } \\
\text { la víctima }\end{array}$ & $\begin{array}{l}\text { Intervención } \\
\text { de la direc- } \\
\text { ción: } \\
\text { Las personas } \\
\text { en posiciones } \\
\text { jerárquicas } \\
\text { altas tienden } \\
\text { a reducir la } \\
\text { situación a } \\
\text { un conflicto } \\
\text { entre partes y } \\
\text { evitan asumir } \\
\text { su responsa- } \\
\text { bilidad como } \\
\text { líderes en la } \\
\text { organización. }\end{array}$ & $\begin{array}{l}\text { Solicitud de } \\
\text { ayuda a espe- } \\
\text { cialistas: } \\
\text { La vícti- } \\
\text { ma busca } \\
\text { ayuda en la } \\
\text { medicina, } \\
\text { alopática u } \\
\text { homeopática. } \\
\text { Sin embar- } \\
\text { go, muchas } \\
\text { veces no son } \\
\text { diagnostica- } \\
\text { dos correcta- } \\
\text { mente. }\end{array}$ & $\begin{array}{l}\text { Salida de la } \\
\text { organización: } \\
\text { Se busca que } \\
\text { la víctima } \\
\text { abandone su } \\
\text { trabajo. }\end{array}$ \\
\hline
\end{tabular}

Fuente: Elaboración propia con base en el material de autores citados.

Al compartir con el sujeto de investigación 1 las fases del mobbing, él comentó:

Nunca pude entender por qué me dejó de hablar. Yo traté de comunicarme con... pero fue imposible. Le llamé varias veces, solicité una cita formal, le envié correos electrónicos, pero nunca me respondió... aun hoy no sé qué fue lo que generó la situación, no sé qué fue lo que hice o cuándo, solo sé que me sentí morir, que cada día que pasaba caía en un vacío cada vez más grande... llegué al extremo de pasar fines de semana enteros sin levantarme de mi cama, sin dormir, sin comer, y aun cuando trato de recordar qué hizo que la relación se deteriorara tanto, no sé qué pasó... no sé qué generó tanto problema...

Tal como puede apreciarse en la reacción del sujeto 1, y siguiendo el modelo de Leymann, probablemente se generó una situación entre ambas personas que fue percibida de manera muy negativa por una de las partes (la agresora) mientras que para la otra (la víctima) fue indiferente, y para quien la situación que se presentó no tuvo y aún no tiene explicación. Esta situación es un ejemplo evidente de un conflicto no resuelto apropiadamente.

Por su parte, el sujeto 2 se siente identificado con el modelo de Martel y Mateo al afirmar:

Yo no entendía qué pasaba, así que después de tratar de buscar una solución directa y no encontrarla busqué al superior de mi jefe para conversar sobre el problema que estaba pasando pero esta persona simplemente me dijo que tratara de comprender la presión de mi jefe, los problemas que tenía. Es decir, lo que me dijo fue no diga nada, yo no puedo hacer nada. Busqué entonces ayuda de alguien 
más cercano a mi jefe y lo que me dijo fue que aguantara un poco más y que si yo podía, que me fuera y buscara otro trabajo, lo que me pareció muy injusto. Yo me había esforzado mucho por mi trabajo, por qué tenía que irme si no había hecho nada malo.

Aun cuando ambos investigadores presentan algunas diferencias en términos de categorización de fases, el fin último de esta práctica es el mismo: la salida de la persona de la organización o su invisibilización.

\section{El mobbing como maniobra para disminuir costos}

En las organizaciones, ocasionalmente y debido a crisis económicas, se pueden generar prácticas por mobbing como estrategias para reducir el número de colaboradores. López y Seco (2016) aseveran que: "Decidida a reducir costos laborales, la empresa cambia las reglas del juego, moviliza sus recursos de poder en los marcos institucionales para garantizar el nuevo orden social y lograr un cambio cualitativo y eventualmente cuantitativo de los trabajadores" (p. 369). Este tipo de estrategias persigue desestabilizar al trabajador y generar inseguridad; esta sensación impactará el clima y la cultura organizacional de la institución. Noam Chomsky (2015) afirma, en Requiem for America, que si la empresa "keep[s] workers insecure, they are going to be under control, ," siendo el mismo principio que parece seguir el fenómeno de acoso para poder contraer costos.

5 Si la empresa mantiene a los trabajadores bajo situaciones de inseguridad, los podrá mantener controlados. (Mi traducción)
Este tipo de estrategia genera, de manera indirecta, un gran impacto en el clima organizacional al perjudicar las relaciones de compañerismo entre los colaboradores de la organización. López y Seco (2016) declaran que este tipo de "(...) estrategia empresarial de reducción de costos desencadena la destrucción de acuerdos y relaciones laborales basadas en la confianza, en un marco de conflictos y tensión entre los compañeros de trabajo, además del deterioro de las relaciones basadas en la solidaridad" (p. 370). Al perderse la confianza en los colegas y compañeros de trabajo, el ambiente de trabajo (clima organizacional) se verá, sin lugar a dudas, afectado. En una institución de educación superior pública esta estrategia afectará también el curriculum oculto existente, es decir aquella percepción del docente en relación con las costumbres, creencias, lenguaje y símbolos de la organización.

Este tipo de cultura organizacional podrá generar comunicación negativa, que tal como afirma Seguin (2016), se compone también de

(...) rumours, complaints (often anonymous), conniving looks, mocking, gossip, misrepresenting facts, insinuations, hearsay, defamation, lies, secret meetings to discuss "the case," disparaging comments, police-like surveillance of the target's work and private life to gather "evidence" that justifies the aggression, and so on ${ }^{6}$.

6 (...) rumores, quejas (a menudo anónimas), miradas confabuladoras, burla, chisme, interpretaciones erróneas de hechos, insinuaciones, comentarios de pasillo, difamación, mentiras, reuniones secretas para discutir "el caso," comentarios despreciativos, supervisión continua del trabajo y vida privada de la persona para recopilar información que justifique la agresión. (Mi traducción) 
Si la descripción que hace Seguin de la academia se percibe como cierta, probable sería también el hecho de que la mayoría de los docentes universitarios pueden haber participado de una cultura organizacional que tiende a promover el mobbing. Ya sea que lo inicie una persona, o grupo de individuos, es responsabilidad de todos los miembros de la institución buscar el ideal de transparencia en todas las acciones en que se ven circunscritos, no solamente en la utilización de recursos públicos.

\section{El mobbing como resultado de la cultura organizacional}

Cada organización creada generará una cultura organizacional propia, teniendo así una identidad que la representa. La cultura organizacional estará influenciada por suposiciones y creencias que a su vez son generadas por lo que los individuos pueden observar, escuchar, aprender y practicar. Para Bernabé, Salas y Arriola (2005): "La cultura organizacional se refiere a los aspectos de la vida organizacional como historias que cuentan a los nuevos miembros para explicar cómo se hacen las cosas, la organización de las oficinas y los objetos personales, las bromas, la atmósfera de trabajo, las políticas oficiales, las relaciones para reportar, entre otros aspectos" (p. 113); consecuentemente, la cultura organizacional es y está en todas las áreas de la institución.

En una organización de educación superior estatal, la cultura organizacional debería de reflejar la excelencia en la enseñanza, la investigación y el aporte a la sociedad que toda la comunidad busca; sin embargo, no siempre es así. Se pueden presentar ocasiones en que las asignaciones de plaza en propiedad, asignación de cursos y nombramientos en cargos superiores aun cuando están basados en la categoría académica del docente, también se toman en cuenta otras variables menos transparentes. López y Seco (2016) declaran que:

Si bien el cargo puede ser otorgado por la capacidad y la competencia profesional del beneficiado, lo que fundamenta su ingreso son las relaciones de confianza y lealtad para con el político de turno, quien puede ejercer el poder para beneficio propio y requiere lealtades basadas en códigos de silencio o de plena subordinación, sin ningún tipo de cuestionamiento ni crítica. Este tipo de reglas de juego da pie a la corrupción, la cual se convierte en un habitus a tal punto que se institucionaliza como forma de gestión, favoreciendo prácticas de mobbing (p. 375).

Esta situación descrita por los investigadores puede presentarse en la academia; algunos ejemplos son los códigos de silencio y la aceptación de decisiones, que los líderes han tomado, que deben ser incuestionables; en el momento en que se razonen, el docente se podrá considerar desleal, lo que redundará en ataques profesionales $\mathrm{y} / \mathrm{o}$ personales, directos $\mathrm{o}$ indirectos, que en el futuro podrían constituirse en mobbing.

\section{Reflexiones}

Al iniciar la investigación sobre este tema, se apreció que debido a la relevancia del tema y su limitado número de estudios en América Latina, se justifica la labor realizada. De la misma manera, al concluir este trabajo se reconoce la importancia 
que tiene su investigación para una mejor comprensión de prácticas negativas que pueden formar parte de la cultura organizacional de una institución.

Por otra parte, y sin demeritar otros tipos de labor profesional, el rol del docente fue, es y será fundamental en el desarrollo de las personas por medio de los procesos de enseñanza-aprendizaje en que se ven circunscritos ya que impactan directamente a las naciones en el área social, económica y política. Al considerar algunas de las características que deben de tener los docentes, Ross (1973) sostiene que en las instituciones de educación superior se debe enfatizar " ... the importance of morality, integrity and spiritual qualities in the teacher if he was to fulfil his role as a leader in the community ${ }^{7 "}$ (p. 107). Aun cuando el artículo de Ross fue publicado hace 45 años, su apreciación es aún vigente, no solo para la academia sino también para todos los ámbitos laborales. Cuando en una institución de educación el $m o b$ bing es aceptado, de manera directa o indirecta, se lesiona la comunidad académica quien a su vez perjudicará a la sociedad con la cual debe contribuir.

No puede negarse que las situaciones de conflicto entre pares y superiores han existido y existirán; sin embargo, el fenómeno del mobbing va más allá de un conflicto aislado entre compañeros de trabajo que pudiera presentarse en una organización. Este fenómeno es complejo y afectará negativamente la cultura organizacional de cualquier institución, tanto privada como

7 “... la importancia de la moral, la integridad y las cualidades espirituales en el docente si él quiere cumplir con su rol como líder de la comunidad." (Mi traducción) pública. Es así como si un individuo está siendo sujeto de mobbing, su afectación será directa, lo que repercutirá en su competitividad, por lo que los productos esperados de él no serán, probablemente, los adecuados, siendo también otros los afectados indirectamente. En consecuencia, se puede afirmar que si bien este tipo de acoso se enfoca en una víctima, la organización, como unidad, también se verá aquejada. Si se piensa en un docente universitario, su afectación podrá percibirse en:

- $\quad \mathrm{Su}$ desempeño en el aula, siendo los estudiantes los perjudicados;

- Su colaboración en los departamentos en que tenga cursos/proyectos asignados;

- Su relación profesional con colegas y personal institucional en general;

- Su identificación con la institución; al final del día se labora por un salario que se necesita;

- Su motivación, intrínseca y extrínseca, para participar en proyectos/ programas de investigación, cultura y apoyo a las comunidades.

Además de estas consecuencias, pueden existir otras que afecten la organización. Una de ellas es la normalización del mobbing hacia miembros de la comunidad académica por medio de acciones consideradas "sin relevancia," y que Seguin (2016) mencionó: los rumores, la difamación, el chisme y los comentarios de pasillo, entre otras. Probablemente, muchos académicos han estado presentes en reuniones/ conversaciones poco productivas en las que el objeto de discusión es una persona específica y las "equivocaciones" que comete; sin embargo, habría que investigar 
el número de ocasiones en que se conversa asertivamente con la "persona problemática" para exponer la situación(es) en discusión. Habría que reflexionar también sobre prácticas tales como:

- Las declaraciones públicas con verdades incompletas generadas para desprestigiar la labor profesional de un colega;

- las decisiones "administrativas" de los líderes para prescindir de la "persona problemática" del departamento;

- el temor a conversar abiertamente sobre posiciones "contrarias" a las del gerente educativo por las posibles repercusiones;

- el temor a enfrentar situaciones de acoso, de cualquier tipo, por la preocupación de ser considerado "problemático."

Las relaciones entre seres humanos siempre han presentado sus altos y bajos, de eso no hay duda; lo que no se puede ni se debe permitir es que cada uno de los miembros de una organización académica acepte ser parte del mobbing, o de cualquier otro tipo de acoso. Si la mayoría de docentes-investigadores en la academia participan o han participado de este tipo de prácticas, se puede afirmar que son todos responsables de que fenómenos como el mobbing se normalicen. En consecuencia, la responsabilidad es conjunta.

\section{Futuras líneas de investigación}

Este trabajo presenta una visión general del fenómeno del mobbing en el ambiente académico universitario. Se enfocó en un estudio exploratorio de lo que este tipo de acoso es y representa y de las razones por las que podría existir en las organizaciones. Considerando futuras líneas de investigación en relación con esta materia, se presentan las siguientes posibilidades:

- Realizar un estudio de campo con el fin de determinar la percepción que académicos de diferentes áreas de conocimiento tengan sobre el mobbing.

- Explorar las posibles medidas existentes para tratar de impedir este tipo de acoso en el trabajo.

- Analizar las posibles diferencias que pudieran existir entre las variables género y hostigamiento laboral.

- Examinar el acoso laboral horizontal y su impacto en el clima laboral y cultura organizacional del lugar de trabajo.

\section{Referencias}

Arciniega, R. S. (2009). El acoso moral (mobbing) en las organizaciones laborales. Psicología Iberoamericana, julio-diciembre, 13-23.

Barón D. M., Munduate J. L., Blanco B., M. J. (2003). La espiral del mobbing. Papeles del Psicólogo, eneroabril, 71-82.

Bartolomé, P. (2012, mar 08). Acoso laboral en el siglo XXI. Diario Médico. Recuperado de https://search.proquest.com/docview/964278501?ac countid=32236

Bernabé González, T. B ., Arriola Miranda, M. A., Salas Rivera, É. (2011). El clima como manifestación objetiva de la cultura organizacional. Revista Ciencias Estratégicas, pp. 109-127. Recuperado de http://www.redalyc. org/articulo.oa?id=151322413008 
Blasco, S. M. y Trenc, J. E. (2010). Mobbing: ¿un problema de perfiles psicológicos o un problema de organización del trabajo? dos estudios de caso/Mobbing: A psychological profiles problem or a work organization problem? two case studies. Cuadernos De Relaciones Laborales, 28(2), 233-255. Recuperado de https://search.proquest.com/docvie w/853265286 ?accountid=32236

Fernández, M. A., López, M., Torres, M., Espinoza, D., Díaz, G., Aguilera, M., Pozos, E. (2012). Autopercepción de presuntos perpetradores de acoso psicológico en el trabajo. Un acercamiento fenomenológico. $\mathrm{Sa}$ lud Uninorte, 28(1) Recuperado de https://search.proquest.com/docvie w/1436222979? accountid=32236

Flores, M., De la Luz Valderrabano, M. y Mendoza, R. (2007). Mobbing: Historia, causas, efectos y propuesta de un modelo para las organizaciones mexicanas. Innovar: Revista De Ciencias Administrativas $Y$ Sociales, 17(29), 71-92. Recuperado de http://www.jstor.org/ stable/23741459

Fondevila, G. (2008). El hostigamiento laboral como forma de discriminación: Un estudio cualitativo de percepción / Harrassment at the Workplace as a Form of Discrimination: A Qualitative Study of Perceptions. Revista Mexicana De Sociología,70(2), 305-329. Recuperado de http://www.jstor.org/ stable/20454335
Gómez, J.A. (2015, dic 16). En guerra contra los acosadores. El Mundo. Recuperado de https://search.proquest.com/docview/1749064712?a countid=32236

Hutchinson, P. y Nyks, K. (2015). Requiem for America. Recuperado de: https://www.youtube.com/ watch? $\mathrm{v}=\mathrm{bX} 3 \mathrm{kEehmBpE}$

Ibarra, L., Escalante, A., Mendizábal, G. (2015). El acoso laboral entre los trabajadores universitarios. RICSH Revista Iberoamericana de las Ciencias Sociales y Humanísticas [en línea], 4 (enero-junio). Recuperado de: <http://www.redalyc.org/articulo.oa? $\mathrm{id}=503950655001>$ ISSN

Justicia, F., Benítez, J. L., Fernández de Haro, E., Berbén, A. G. (2007). El fenómeno del acoso laboral entre los trabajadores de la universidad. Psicologia em Estudo, diciembre, 457-463.

López-Cabarcos, M. A., Vázquez-Rodríguez, P., Montes-Piñeiro, C. (2010). Mobbing: Antecedentes psicosociales y consecuencias sobre la satisfacción laboral. Revista Latinoamericana de Psicología, sin mes, 215-224.

López, M. A., Vázquez, P., Montes, C. (2012). Perfil de la víctima de mobbing en Galicia. Especial atención a las diferencias de género. Revista Galega de Economía, sin mes, 1-19.

López, C. M., Seco, E. (2016). Tipología de Mobbing - una mirada desde la responsabilidad de la empresa. Sociologías, septiembre-diciembre, 364-401. 
Mantilla, J. y Díaz, M. (2012). El síndrome de Burnout en el profesorado de Secundaria y su relación con variables personales y profesionales. Revista Española De Pedagogía, 70(252), 259-277. Recuperado de http://www.jstor.org.ezproxy.sibdi. ucr.ac.cr:2048/stable/23766771

Marente, J. A. A. y Gestoso, C. L. G. (2008). Burnout y mobbing en enseñanza secundaria. Revista Complutense De Educación, 19(1), 157173. Recuperado de https://search. proquest.com/docview/220934194 ?accountid $=32236$

Martel, M. C. V. y Mateo, R. S. (2012). El mobbing: ¿el crimen perfecto? No, qué más quisieran "algunos"*/mobbing: the perfect crime? Not really, but some wish it was/o mobbing: ¿o crime perfeito? Não, o que mais gostariam "alguns"/l'harcèlement moral: le crime parfait? Criterio Libre, 10(17), 148-175. Recuperado de https://search.proquest.com/ docview/1322998153?account $\mathrm{id}=32236$

'Mobbing' y dignidad. (17 de agosto de 2013). La Nación. Recuperado de http://www. nacion.com/opinion/foros/mobbing-y-dignidad/KIMA27GNVNHTVJUHUK VAAAHKCY/ story/

Olmedo, M. y González, P. (2006). La violencia en el ámbito laboral: la problemática conceptuación del mobbing, su evaluación, prevención y tratamiento/violence in working settings: the problematic concept of mobbing, its assessment, prevention and treatment. Acción Psicológica, 4(2), 107-128. Recuperado de https://search.proquest.com/docvie w/1271628000 ?accountid=32236

Pinzón de Bojana, B. y Atencio, E. (2010). El mobbing en el desempeño laboral. Implicaciones en la salud. Multiciencias [en línea], 10 [Fecha de consulta: 28 de agosto de 2017] Disponible en:<http://www.redalyc. org/articulo.oa?id=90430360026> ISSN 1317-2255

Peralta, M. C. (2004). El acoso laboralmobbing-perspectiva psicológica. Revista de Estudios Sociales, agosto, 111-122.

Prakash, V. (2011). Concerns about Autonomy and Academic Freedom in Higher Education Institutions. Economic and Political Weekly, 46(16), 36-40. Recuperado de http://www. jstor.org/stable/41152104

Ross, A. (1973). The Role of Higher Education Institutions in National Development. Higher Education, 2(1), 103-108. Recuperado de http:// www.jstor.org/stable/3445764

Trujillo, M. M., Rivas, L. A., Lámbarry, F. (2014). Mobbing: A theoretical model quantifying factors affecting the role of women executives in the institutions of public education in Mexico. Contaduría y Administración, enero-marzo, 195-228.

Varela, O., Puhl, Stella M., Izcurdia, M. A. (2013). Clima laboral y mobbing. Anuario de Investigaciones, 23-26. 